\title{
O Museu da Solidariedade do Chile e Mário Pedrosa
}

Ana Flávia Zoli

\section{Resumo:}

O objetivo deste trabalho é abordar a criação do Museu da Solidariedade no Chile, ocorrida no governo de Salvador Allende. Buscou-se delimitar também a grande participação, na fundação deste Museu, do crítico de arte brasileiro Mário Pedrosa, que se encontrava refugiado no Chile no início da década de I970.

Palavras-chave: Museu da Solidariedade - Mário Pedrosa - Salvador Allende - Ghile 


\section{Introdução}

Em um dos momentos mais distintos dos últimos trinta anos da história da América Latina, é fundado no Chile um museu de arte contemporânea que, diferentemente de outros museus, possui em sua concepção uma característica única: a solidariedade. As obras do Museu da Solidariedade do Chile foram doadas espontaneamente pelos artistas plásticos que realmente acreditavam e apoiavam a transformação política e social pela qual passava o país, muitos doaram e tantos outros ajudaram a edificar este singular museu. Entre eles está o crítico de arte e militante político brasileiro, Mário Pedrosa. Para ele, a criação deste Museu contribuiria diretamente com a criatividade popular, devendo ser o lugar "das expressões culturais mais fecundas do novo Ghile, como consequência de seu avanço no caminho do socialismo". ${ }^{\text {I }}$

\section{A Concepção do Museu}

Nos anos de I970 a I973, o Ghile passou por sua experiência socialista. Diferentemente dos outros países socialistas que optaram pelo caminho da Revolução armada, como Cuba na América Latina, o Chile optou pela construção do socialismo por via democrática. Nas eleições de I970, Salvador Allende, candidato do partido de esquerda da Unidade Popular, vence as eleições e sobe ao poder.

No programa de governo de Allende há uma medida (a última entre as quarenta a serem empreendidas) que prevê a criação do "Instituto Nacional de Arte e Cultura". ${ }^{2}$ A criação deste Instituto possibilitaria a presença de escolas de formação artística em todas as cidades chilenas. Tal medida demonstra a preocupação que o governo apresentava para com o desenvolvimento e rumo das artes no país.

Outra demonstração desta preocupação foi o apoio de Salvador Allende à criação de um museu de arte contemporânea e experimental, único no mundo, ao qual ele dera o nome de Museo de La Solidariedad con Chile. A ideia foi concebida

I ASSOCIAÇÃO MUSEU AFRO-BRASIL. Museo de La Solidariedad Salvador Allende: Estéticas, Sueños y Utopías de los Artistas Del Mundo pela Libertad: Tributo a Mário Pedrosa: catálogo [São Paulo]: Imprensa Oficial do Estado de São Paulo, [2009]. 290 p. il. Catálogo de exposição. p. 32.

2 Medida de número 40: "Griação do Instituto Nacional de Arte e Gultura. Griaremos O Instituto de Arte e Cultura e Escola de formação artística em todas as cidades”. Unidad Popular. Las primeras 40 medidas del Gobierno Popular - Programa de Gobierno de Salvador Allende, Chile, I970. Disponível em: $<$ http://www.fundacionsalvadorallende.cl/enlacesalida2.php?num=9II4 >. 
pelo crítico de arte espanhol José Maria Moreno Galván, que a expôs na reunião "Operación Verdad". Esse encontro internacional foi organizado por Allende no ano de I97I em Santiago com o intuito de apresentar seu projeto de governo para obtenção de apoio dos intelectuais convidados. Além de Galván, encontravam-se presentes também os críticos de arte Giulio Carlo Argan e o brasileiro Mário Pedrosa. ${ }^{3}$

O crítico de arte e militante político brasileiro se achava refugiado no Chile devido à ditadura militar e civil no Brasil. A prisão preventiva de Mário, acusado de envolvimento com as denúncias realizadas à Anistia Internacional sobre casos de tortura no Brasil, é decretada em julho de I970 pelo governo brasileiro. ${ }^{4}$ Para evitar a prisão, resolve se exilar na embaixada do Chile, onde aguarda três meses por permissão para poder viajar para aquele país. Já em terras chilenas, trabalha com Miguel Rojas Mix no Instituto de Arte Latinoamericano da Universidade do Ghile.

\section{A Concretização do Museu da Solidariedade e a Participação Fundamental de Mário Pedrosa}

Para concretizar o projeto do museu, Allende contou com o trabalho de Pedro Miras, do pintor e diretor da Faculdade de Belas Artes da Universidade do Ghile José Balmes e, especialmente, de Mário Pedrosa. Este estava entusiasmado com a possibilidade de se criar no Ghile, que passava por um momento político particular, um museu até então não existente no mundo. Seria único na história, pois receberia a contribuição direta dos artistas, não passando por colaboradores, apoios ou mecenas. ${ }^{5}$ As obras proviriam unicamente da solidariedade dos artistas plásticos para com o povo chileno, que passava pela experiência socialista.

O crítico brasileiro sentia-se realizado, pois sabia que vivia um momento único. De acordo com suas ideias, esse momento político por qual passava o Chile, seria um momento em que a arte iria desempenhar um papel

3 Gf. AMARAL, Aracy A. "Chile: a volta do Museu da Solidariedade”. In: Textos do Trópico de Capricórnio: artigos e ensaios (1980-2005).v.2. São Paulo: Ed. 34, 2006. p. 97.

4 MARTINS, Luciano. "A utopia como modo de vida - Fragmentos de lembrança de Mario Pedrosa". In.: MARQUES NETO, José Castilho. Mario Pedrosa e o Brasil. São Paulo: Editora Fundação Perseu Abramo, 200I.

5 Gf. PEGGinini DE AlVARADO, Daisy V. M. "O Museu de La Solidariedad com Chile”. In.: AMARAL, Aracy A.; ARANTES, Otília. Mario Pedrosa: 100 anos. São Paulo: Fundação Memorial da América Latina, 2000. p. I7. 
fundamental, seu uso e direcionamento trariam condições para a vitória da luta pelo socialismo. Para Mário, "a luta pelo socialismo é a luta pela cultura", 6 por isso que o desenvolvimento cultural e artístico da transformação que ocorria no Chile deveria ser confiado aos artistas (aos que já existiam e aos que estavam por vir) e estes deveriam ser solicitados e gerar iniciativas.

Suas ideias de transformação levavam em conta a participação de toda a sociedade artística chilena afim da mudança social que se iniciava no país:

Pode-se assumir que o Chile é apenas um projeto coletivo para o qual os artistas de todas as categorias - dos artesãos aos eruditos, dos moveleiros aos arquitetos trarão sua parte de criatividade, com disciplina e entusiasmo, mas em plena liberdade criativa. ${ }^{7}$

Segundo Mário, como a transformação da sociedade chilena se daria gradualmente, seria de extrema importância a criação de uma política cultural adequada. Tal política visaria à importação de tudo o que servisse para o desenvolvimento do modelo político chileno e o total bloqueio a tudo que fosse contrário a esse desenvolvimento ${ }^{8}$ A criação do Museu da Solidariedade seria o acontecimento perfeito para a efetivação desta política, pois permitiria, por meio da doação das obras, a demonstração de solidariedade daqueles artistas que realmente acreditassem no projeto de Salvador Allende.

A fim de que a ideia se concretizasse, Mário cria e preside o "Comitê Internacional de Solidariedade Artística com o Chile", do qual participavam artistas, críticos de arte e diretores de museus de vários países. ${ }^{9}$ Pedrosa usa de seu respeito, prestígio e conhecimento conseguidos como crítico de arte para mobilizar artistas plásticos do mundo inteiro. ${ }^{\text {Io }}$ As embaixadas

6 Em seu caso, o militante político nunca esteve separado do crítico de arte. Cf. PEDROSA, Mário. "O modelo chileno de socialismo e a Frente das artes". ARANTES, Otília (org.). Política das artes. Textos escolhidos I. São Paulo: Edusp, I995· p. 3I7.

7 Ibid., p. 320. Grifo do autor, pois para Pedrosa de nada adiantaria a liberdade criativa do artista se este somente se propusesse a realizar qualquer obra de arte sem disciplina e entusiasmo pelo momento político que o Chile passava. Este posicionamento político e reflexivo faria que o artista não reproduzisse exatamente o que o mundo capitalista reificado desejasse, mas produzisse, por meio de sua liberdade criativa, obras de arte que ajudassem no desenvolvimento do novo modelo socialista almejado.

8 Ibid., p. 3i8.

9 Como o pintor e escritor italiano Carlo Levi, a crítica e historiadora estadunidense Dore Ashton, o poeta espanhol Rafael Alberti e o crítico José Maria Moreno Galván.

Io "Entre as idas e vindas do militante, surge o crítico. Entre os exílios, surge o agitador das artes. O militante se faz crítico e o crítico se faz agitador cultural”. Cf. ALAMBERT, Francisco. "Mario Pedrosa. 
do Ghile se transformaram em receptores das doações, sendo que algumas obras chegavam diretamente ao Instituto de Arte Latinoamericano em Santiago. ${ }^{\text {II }}$

Em cartas, nota-se a preocupação e vontade do crítico para que o projeto acontecesse e também sua euforia com as diversas doações que chegavam. Segundo ele, obras chegavam da Itália, Estados Unidos, Suíça, Alemanha, Japão, de Paris chegavam obras dos brasileiros refugiados como Lygia Clark, Sérgio Camargo, Arthur Luiz Piza, Sérvulo Esmeraldo, Frans Krajcberg e Flávio Shiró. Uma das obras que mais o contentaram foi a grande tela doada por Miró, realizada especialmente para o Chile.

A inauguração do Museu da Solidariedade coincidiu com uma grande conferência da ONU para o comércio e desenvolvimento que ocorria no Chile, a UCTAD 3. Este acontecimento permitiu que diversos delegados da UCTAD estivessem presentes no ato que consolidou a inauguração e primeira edição do Museu, ocorrida em um parque do Museu de Arte Contemporânea da Universidade do Chile, chamado "Quinta Normal".

No dia I7 de maio de I972, ocorre o ato de inauguração do Museu. Mário Pedrosa profere o seu discurso diante do quadro de Miró, para ele a figura representada na obra é um "galo cantando a alvorada" de um novo tempo, uma nova época que estava nascendo. ${ }^{12}$ Salvador Allende em seu discurso agradece a atitude solidária dos artistas que doaram e ainda doariam obras para o povo do Chile, agradece também àqueles, que como Pedrosa, haviam conseguido doações por meio de seus contatos e influências. Parafraseando Mário, Allende diz que aquele não seria somente um museu, mas seria o Museu dos Trabalhadores, lugar em que a cultura não seria mais um patrimônio da elite, mas daqueles que haviam sido renegados até então, como os trabalhadores da terra, da usina, das fábricas e do litoral.

Política e arte em revolução”. In.: FERREIRA, Jorege; REIS, Daniel Aarão (orgs.). A formação das tradições (1889-1945). Rio de Janeiro: Givilização Brasileira, 2007·p. 4IO.

II Outro acontecimento em que foi possível ver o reconhecimento e respeito dos artistas para com Pedrosa foi a VI Bienal do Museu de Arte Moderna de São Paulo (I96I) a qual ele dirigiu. Vieram para o Brasil obras do Paraguai, Iugoslávia, Austrália, Japão, Índia, União Soviética, Hungria, Romênia, Bulgária e Cuba. Cf. ALAMBERT, Francisco. "Mario Pedrosa e a Bienal (moderno, primitivo, nacional e internacional)”. In.: ABDALA JR., Benjamin; CARA, Salete de Almeida. Moderno de nascença - figurações críticas do Brasil. São Paulo: Boitempo, 2006.

I2 Em uma de suas cartas deixa explicito a importância do quadro de Miró: "O Miró mandou um galo, que tem servido de prato de substância para a propaganda (...). Tornou-se um símbolo para a retórica museográfica.” Cf. FIGUEIREDO, Carlos Eduardo de Sena. Mario Pedrosa, retratos do exílio. Rio de Janeiro: Edições Antares, I982. p. I9. 
Allende assegurava a Mário Pedrosa que o museu se manteria, e que se ampliaria graças às muitas obras que haviam de chegar mandadas pelos artistas progressistas do mundo para o patrimônio cultural do povo do Ghile. Também faz um agradecimento a Miró pela sua criação realizada especialmente ao povo chileno, ao galo que:

...como disse o companheiro Pedrosa: "canta uma nova alvorada", uma alvorada que é uma vida distinta, em um país dependente que rompe as amarras para derrotar o subdesenvolvimento e com isso a ignorância, a miséria, a incultura, a doença. ${ }^{13}$

Por meio do agradecimento a Miró, Allende e o povo do Chile agradeciam aos outros artistas que haviam compreendido a luta chilena frente aos interesses poderosos daqueles que desejavam que o povo seguisse sem instrução e cultura.

Depois da inauguração e da exposição, as obras expostas seguiram, a pedido de Allende, para o prédio especialmente construído para a UGTAD 3 e que, posteriormente, abrigaria o Instituto Nacional de Arte e Cultura. Obras estas dificilmente vistas em museus de arte contemporânea da América Latina, como as de Vasarely, Frank Stella, Tápies, Alexander Calder, César, Soulages, Julio

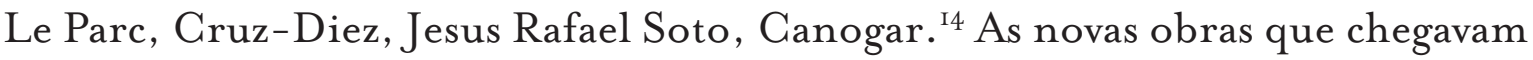
também rumavam para este edifício.

No final do ano de 1972, uma grave crise havia se instaurado contra o governo de Allende. Mesmo assim, as doações não paravam de chegar, como a do artista conceitual da Califórnia chamado Rusha que constava de uma série de fotografias sobre marcas impressas no asfalto de uma rodovia. Para Pedrosa, este gesto do artista era uma demonstração de generosidade "suprapartidária, supranacional", como ele próprio repetia frequentemente "a arte é o exercício experimental da liberdade". ${ }^{15}$

Em meados de I973, a situação do governo se agravava ainda mais, a falta de alimentos e combustíveis e a crise econômica demonstravam a situação frágil pela qual o Ghile de Allende passava. Isso não impedia a solidariedade dos artistas que mandavam cada vez mais obras para o povo chileno. Esta difícil situação também não esmorecia o desejo de ver o Museu pronto. Mário realizara

I3 Ver Anexo I - Discurso de Salvador Allende na Inauguração no Museu da Solidariedade - Quinta Normal, I7 de maio de I972. Disponível em: <http://www.fundacionsalvadorallende.cl/enlacesalida. php? num=7007>.

I4 AMARAL, op. cit., p. 97.

I5 ALVARADO, op. cit., p. 2I. 
neste ano diversas viagens para a Europa a fim de estabelecer mais contatos e continuar divulgando a causa a favor do Chile.

No dia II de setembro, é desferido o golpe militar. Mário Pedrosa em novo exílio, desta vez no México, continua a se preocupar com o projeto que tanto ajudou a erguer. Ele mesmo concebeu a ideia de converter o Museu da Solidariedade em um museu itinerante, seria um "símbolo da resistência", pois havia sido "feito para o povo do Chile, para os trabalhadores do campo e da cidade" ${ }^{16}$ não sendo adequado ficar sob o jugo dos militares.

Assim sendo, criou-se no exílio um Comitê que recebeu o nome de Museu da Resistência Salvador Allende. Mais obras de arte provenientes de diversos países foram doadas, exposições foram realizadas em vários lugares da Europa, como na França e Inglaterra. Com o retorno da democracia no Ghile, e como sonhado por Mário Pedrosa, em I990 o museu foi reorganizado e renomeado de Museu da Solidariedade Salvador Allende.

\section{Considerações Finais}

Hoje, o Museu ainda recebe doações de muitos artistas que se solidarizam com a sua história, e que apoiam a manutenção deste Museu que foi desmantelado pela ditadura militar chilena. Ele pertence à Fundação Salvador Allende que é presidida pela filha do ex-presidente, Isabel Allende, e tem sua sede em um antigo casarão em Santiago. Porém, nos fica a pergunta: será que como Mário tanto queria, o Museu da Solidariedade continua a exercer o pensamento político nas Artes e ainda se engaja na educação do povo chileno, como tanto desejava Allende?

Vemos na história deste museu a participação de um brasileiro que, sempre acreditando no poder transformador da arte, viu, novamente nela, a possibilidade de mudança da realidade. Neste caso, as obras e o Museu da Solidariedade, destinados ao povo chileno, teriam papel central para o desenvolvimento da liberdade que traria a sensibilidade para o homem do novo Ghile que estava por surgir. Sempre um homem de ação, Mário Pedrosa nunca perdeu o otimismo de ver esta transformação acontecer e junto dela vir o amanhecer de um novo tempo.

I6 Ibid., p. 23. 


\section{Referências Bibliográficas}

AGIO, Alberto. Democracia e Socialismo. São Paulo: Annablume, 2002.

ALAMBERT, Francisco. "Mario Pedrosa. Política e arte em revolução". In.: FERREIRA, Jorege; REIS, Daniel Aarão (orgs.). A formação das tradições (18891945). Rio de Janeiro: Givilização Brasileira, 2007.

- "Mario Pedrosa e a Bienal (moderno, primitivo, nacional e internacional)". In.: ABDALA JR., Benjamin; CARA, Salete de Almeida. Moderno de nascença - figurações críticas do Brasil. São Paulo: Boitempo, 2006.

AMARAL, Aracy A. Textos do Trópico de Capricórnio: artigos e ensaios (1980-2005). v. 2. São Paulo: Ed. 34, 2006.

AMARAL, Aracy A.; ARANTES, Otília. Mario Pedrosa: 100 anos. São Paulo: Fundação Memorial da América Latina, 2000.

ASSOCIAÇÃO MUSEU AFRO-BRASIL. Museo de La Solidariedad Salvador Allende: Estéticas, Sueños y Utopías de los Artistas Del Mundo pela Libertad: Tributo a Mário Pedrosa: catálogo [São Paulo]: Imprensa Oficial do Estado de São Paulo, [2009]. 290 p. il. Catálogo de exposição.

FIGUEIREDO, Carlos Eduardo de Sena. Mario Pedrosa, retratos do exílio. Rio de Janeiro: Edições Antares, I982.

MARQUES NETO, José Castilho (org.). Mario Pedrosa e o Brasil. São Paulo: Editora Fundação Perseu Abramo, 200 I.

PEGGININI DE ALVARADO, Daisy V. M. "O Museu de La Solidariedad com Chile”. In.: AMARAL, Aracy A.; ARANTES, Otília. Mario Pedrosa: 100 anos. São Paulo: Fundação Memorial da América Latina, 2000.

PEDROSA, Mário. "O modelo chileno de socialismo e a Frente das artes". In.: ARANTES, Otília (org.). Política das artes. Textos escolhidos I. São Paulo: Edusp, I995.

SADER, Eder. Um rumor de botas. São Paulo: Polis, I982.

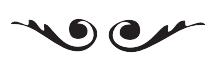


Ana Flávia Zoli é graduanda em História pela USP

E-mail: ana.zoli@usp.br

\section{Sites Consultados}

<http://www.fundacionsalvadorallende.cl/>.

$\langle$ http://www.museodelasolidaridad.cl/index.php>. 



\section{Anexo 1 - Discurso de Salvador Allende na Inauguração do Museu da Solidariedade - Quinta Normal, 17 de maio de 1972}

Señoras, estimados compañeros: Mario Pedrosa, Pedro Miras y José Balmes.

Señores Embajadores, representantes de países amigos.

Señores Delegados a la Tercera UNCTAD. Autoridades civiles, militares y eclesiásticas.

Muy estimadas compañeras y estimados compañeros:

Es para mí un honor, muy significativo, recibir a nombre del pueblo de Chile estas muestras, estos cuadros, estas obras que nos envían, como expresión solidaria, artistas de los distintos continentes.

Quiero destacar que en la profundidad de las palabras y en la belleza de la forma, como corresponde a un artista, el compañero Mario Pedrosa ha señalado que éste es el único museo de mundo que tiene un origen y contenido de tan profundo alcance.

Es la expresión solidaria de hombres de distintos pueblos y razas que, a pesar de la distancia, entregan su capacidad creadora, sin reticencias, al pueblo de Chile, en esta creadora de su lucha. Y lo hacen en los momentos en que también mi Patria es distinguida al señalársele como el lugar para que se reúnan representantes de I4I países en la Tercera Conferencia de Comercio y Desarrollo.

No sólo el pueblo de Chile, sino nuestros visitantes comprenderán, como comprendemos todos, lo que representa para nosotros este estímulo, esta expresión fraterna, esta manifestación comprensiva de los artistas del mundo. 
Comprendo, perfectamente bien, que no puedo dar sencillamente las gracias, aunque esta palabra tiene un contenido tan profundo que podría con ella expresar mis sentimientos y los sentimientos agradecidos de los trabajadores chilenos.

Pero siempre entendí el contenido, el alcance y la significación que han tenido y tendrán estas demostraciones de los creadores de la belleza, de los plasmadores de la inquietud, en sus telas, en sus estatuas, en sus obras.

$\mathrm{Y}$, es por ello que el $\mathrm{I}^{\circ}$ de Mayo, en un acto de masas de honda importancia para nosotros, cuando se congregaban los trabajadores de Chile, para rememorar a aquellos que cayeron para hacer posible - entre otras cosas - que los nuestros se reunieran siendo Gobierno, anuncié que se iba a inaugurar este Museo de la Solidaridad y leí los nombres de aquellos que estimé, representaban, no por jerarquía tan sólo, de sus condiciones de creadores, sino por haber sido los primeros, los nombres - repito - de aquellos que enviaron al Comité de Solidaridad, con más premura, su expresión de afecto a nuestro pueblo y a nuestros trabajadores.

Hoy, quiero, no cumpliendo ritualmente, y en forma protocolar, sino porque estimo que es justo hacerlo, recordar aquí al comité que integraban Louis Aragón, Jean Lamarie, Rafael Alberti, Carlo Levi, Aldo Pellegrini, Mariano Rodríguez y José María Moreno Galván.

Quiero destacar a aquellos que como Mario Pedrosa y Danilo Tréllez fueron los representantes de nuestros artistas para coordinar la entrega y a los compañeros José Balmes y Miguel Rojas y, además, al Decano de la Facultad de Bellas Artes de la Universidad de Chile, Pedro Miras Contreras, quienes también con su ascendiente, sus vínculos, con sus contactos han hecho posible la materialización de lo que hoy día podemos contemplar.

¡Qué bien lo ha expresado el compañero Pedrosa! : este no será un Museo más. Este debe ser el Museo de los Trabajadores, porque para ellos fue donado y cuando el Gobierno Popular que presido, luchó, porque así fue, para que la UNGTAD III pudiera realizarse en Chile, cuando el espíritu de UNCTAD, por así decirlo, sacudió a nuestro pueblo y se hizo posible lo que muchos no creyeron, que íbamos a materializar la construcción de la placa y de la torre que ha servido de edificio material para los delegados de tantos países, entonces, avizoramos lo que será mañana esa torre y lo que será mañana esa placa.

Queremos que esa torre sea entregada, y así lo propondré, a las mujeres y a los niños chilenos, y queremos que esa placa sea la base material del gran Instituto Nacional de la Cultura y, dónde mejor que allí estarán estos cuadros, estas telas y estas obras.

Allá donde van a ir los trabajadores entendiendo que aquí, en una nueva concepción de los derechos del hombre, y trabajando fundamentalmente para el hombre, poniendo la economía a su servicio, queremos que la cultura no sea 
el patrimonio de una élite, sino que a ella tengan acceso -y legítimo- las grandes masas pretéridas y postergadas hasta ahora, fundamentalmente, los trabajadores de la tierra, de la usina, de las empresas o el litoral.

Por eso, compañero Pedrosa, yo le aseguro a usted que este Museo no se va a desmembrar, que este Museo se mantendrá en su integridad y creo que sus palabras señalan también la posibilidad que se amplíe, no porque nosotros lo pidamos, sino porque, seguramente, muchos artistas que no tuvieron oportuna información o tiempo necesario, harán la entrega generosa que usted mismo nos ha anunciado ya, para acrecentar este patrimonio que desde ahora y por mandato de los artistas progresistas del mundo integra el patrimonio cultural del pueblo de Chile.

Quiero, finalmente, señalar que en un hombre, que por sus años, por su prestancia y por su vida, merece que en él exprese mi reconocimiento a los artistas progresistas del mundo, me refiero a Joan Miró, al maestro, o a don Joan, como lo llaman los que así tienen derecho a hacerlo.

El quiso, no entregar un cuadro de los muchos o de los pocos que tiene en su casa, o en su galería de trabajo, él quiso crear algo para Chile. Fue más generoso aún, él puso su inteligencia, sus pinceles, su mente a trabajar para materializar este gallo, que como ha dicho el compañero Pedrosa: "canta una nueva alborada" a una nueva alborada, que es una vida distinta, en un país dependiente que rompe las amarras para derrotar el subdesarrollo y con ello la ignorancia, la miseria, la incultura, la enfermedad.

En Joan Miró, anciano respetado y respetable, pintor sin fronteras rindo el homenaje agradecido del pueblo de Chile, por la actitud de tantos y tantos que han comprendido lo que aquí hacemos, las metas que queremos alcanzar, nuestra dura lucha frente a intereses poderosos - nacionales y extranjeros - que quisieran que el pueblo siguiera aherrojado y al margen de la instrucción y la cultura.

Este Museo será la expresión del estímulo más hondo que sentirán desde más cerca los trabajadores. Y yo puedo decirles que el pueblo de Chile hace suyas las palabras del gran poeta nuestro, Pablo Neruda, cuando pensamos que en el mundo no debe haber fronteras y cuando él dice que "su casa sin puertas es la tierra, y las estrellas del mundo son su patria”. 